\title{
Transition in the fractal geometry of Arctic melt ponds
}

\author{
C. Hohenegger ${ }^{1}$, B. Alali ${ }^{1}$, K. R. Steffen ${ }^{1}$, D. K. Perovich ${ }^{2,3}$, and K. M. Golden ${ }^{1}$ \\ ${ }^{1}$ Department of Mathematics, University of Utah, 155 S 1400 E, RM 233, Salt Lake City, UT 84112-0090, USA \\ ${ }^{2}$ ERDC-CRREL, 72 Lyme Road, Hanover, NH 03755, USA \\ ${ }^{3}$ Thayer School of Engineering, Dartmouth College, Hanover, NH 03755, USA
}

Correspondence to: K. M. Golden (golden@math.utah.edu)

Received: 4 May 2012 - Published in The Cryosphere Discuss.: 15 June 2012

Revised: 19 September 2012 - Accepted: 20 September 2012 - Published: 19 October 2012

\begin{abstract}
During the Arctic melt season, the sea ice surface undergoes a remarkable transformation from vast expanses of snow covered ice to complex mosaics of ice and melt ponds. Sea ice albedo, a key parameter in climate modeling, is determined by the complex evolution of melt pond configurations. In fact, ice-albedo feedback has played a major role in the recent declines of the summer Arctic sea ice pack. However, understanding melt pond evolution remains a significant challenge to improving climate projections. By analyzing area-perimeter data from hundreds of thousands of melt ponds, we find here an unexpected separation of scales, where pond fractal dimension $D$ transitions from 1 to 2 around a critical length scale of $100 \mathrm{~m}^{2}$ in area. Pond complexity increases rapidly through the transition as smaller ponds coalesce to form large connected regions, and reaches a maximum for ponds larger than $1000 \mathrm{~m}^{2}$, whose boundaries resemble space-filling curves, with $D \approx 2$. These universal features of Arctic melt pond evolution are similar to phase transitions in statistical physics. The results impact sea ice albedo, the transmitted radiation fields under melting sea ice, the heat balance of sea ice and the upper ocean, and biological productivity such as under ice phytoplankton blooms.
\end{abstract}

\section{Introduction}

Melt ponds on the surface of sea ice form a key component of the late spring and summer Arctic marine environment (Flocco et al., 2010; Scott and Feltham, 2010; Pedersen et al., 2009; Polashenski et al., 2012). While snow and sea ice reflect most incident sunlight, melt ponds absorb most of it. As melting increases so does solar absorption, which leads to more melting, and so on. This ice-albedo feedback has contributed significantly to the precipitous losses of Arctic sea ice (Perovich et al., 2008), which have outpaced the projections of most climate models (Serreze et al., 2007; Stroeve et al., 2007; Boé et al., 2009). Representing the overall albedo of the sea ice pack is a fundamental problem in climate modeling (Flocco et al., 2010), and a significant source of uncertainty in efforts to improve climate projections.

Despite the central role that melt ponds play in understanding the decline of the summer Arctic sea ice pack, comprehensive observations or theories of their formation, coverage, and evolution remain relatively sparse. Available observations of melt ponds show that their areal coverage is highly variable, particularly for first-year ice early in the melt season, with rates of change as high as $35 \%$ per day (Scharien and Yackel, 2005; Polashenski et al., 2012). Such variability, as well as the influence of many competing factors controlling melt pond evolution (Eicken et al., 2002, 2004), makes the incorporation of realistic treatments of albedo into sea ice and climate models quite challenging (Polashenski et al., 2012). There have been substantial efforts at developing detailed small- and medium-scale numerical models of melt pond coverage which include some of these mechanisms (Flocco and Feltham, 2007; Skyllingstad et al., 2009; Scott and Feltham, 2010). There has also been recent work on incorporating melt pond parameterizations into global climate models (Flocco et al., 2010; Hunke and Lipscomb, 2010; Pedersen et al., 2009).

Here we ask if the evolution of melt pond geometry exhibits universal characteristics which do not depend on the details of the driving mechanisms. Fundamentally, the melting of Arctic sea ice during summer is a phase transition phenomenon, where solid ice turns to liquid, albeit on large 
regional scales and over a period of time which depends on environmental forcing and other factors. As such, we look for features of this important process which are mathematically analogous to related phenomena in the theory of phase transitions (Thompson, 1988; Coniglio, 1989). For example, the behavior displayed by the percolation model for connectedness of the phases in binary composites is similar to melt pond evolution (Stauffer and Aharony, 1992; Torquato, 2002; Christensen and Moloney, 2005). In both cases there is a transition in the global geometrical characteristics of the configurations when the driving parameter exceeds a critical threshold.

\section{Method}

The sea ice surface is viewed here as a two phase composite (Milton, 2002; Torquato, 2002) of dark melt ponds and white snow or ice (Fig. 1). We investigate the geometry of the multiscale boundary between the two phases and how it evolves, as well as the connectedness of the melt pond phase.

We use two large sets of images of melting Arctic sea ice collected during two Arctic expeditions: 2005 HealyOden TRans Arctic EXpedition (HOTRAX) (Perovich et al., 2009) and 1998 Surface Heat Budget of the Arctic Ocean (SHEBA) (Perovich et al., 2002). The sea ice around SHEBA in the summer of 1998 was predominantly multiyear, with coverage greater than $90 \%$ (Perovich et al., 2002). There were a few scattered areas of first-year ice, where leads had opened and frozen during the winter of 1997-1998. The HOTRAX images from 14 August were of a transition zone between first-year and multiyear ice. Ship-based ice observations made on 14 August indicated a 5 to 3 ratio of multiyear to first-year ice (Perovich et al., 2009).

During the HOTRAX campaign, ten helicopter photographic survey flights following a modified rectangular pattern around the Healy were conducted during the transition from Arctic summer to fall (August-September) at an altitude between $500 \mathrm{~m}$ and $2000 \mathrm{~m}$. Images were recorded with a Nikon D70 mounted on the helicopter with the intervalometer set to ten seconds, resulting in almost no photo overlaps. During the SHEBA campaign, about a dozen helicopter survey flights following a box centered on the Des Groseilliers were conducted between May and October, typically at an altitude of $1830 \mathrm{~m}$. Images were recorded with a Nikon $35 \mathrm{~mm}$ camera mounted on the back of the helicopter. Again minimal overlap between pictures was seen.

Recorded images show three distinct and geometrically complex features: open ocean, melt ponds and ice. The HOTRAX images are easier to analyze, as the histograms of the RGB pixel values are clearly bimodal. In this case, ice is characterized by high red pixel values, while water corresponds to lower red pixel values. Moreover, the transition between shallow to deep water follows the blue spectrum from light to dark with ocean being almost black (Fig. 2a).

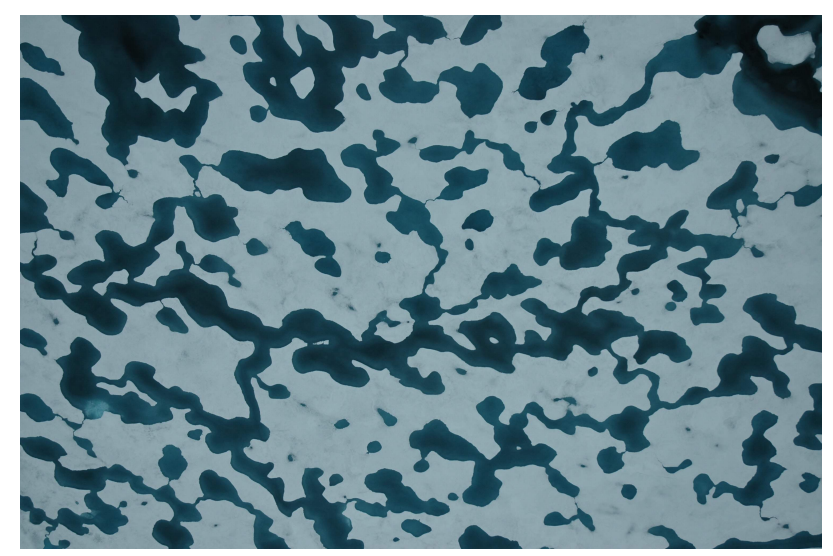

Fig. 1. Complex geometry of well developed Arctic melt ponds. Aerial photo taken 14 August 2005 on the Healy-Oden Trans Arctic Expedition (HOTRAX).

This segmentation (Fig. 2b) introduces errors as some very deep ponds are mislabeled as ocean. To correct this, the directional derivative of the color intensity in each direction or the change in colors surrounding a deep water region is calculated. If the region is part of a melt pond, the change in color in the original is smooth and the directional derivative is continuous in all directions. A discontinuity reveals the transition from ocean to ice or shallow ponds. In the last step, the correctly labeled shallow and deep ponds are combined to produce a white, blue and black image for ice, melt ponds and ocean (Fig. 2c).

Using the segmented images, perimeters and areas of connected melt ponds can be computed with standard image processing tools (MATLAB Image Processing Toolbox). Computed in this manner, the area of a melt pond is the total number of pixels corresponding to the melt pond, while the perimeter of a melt pond is the sum of the distances between adjoining pairs of pixels around the border of the melt pond. For non-singular regions, the calculated perimeter corresponds to the sum of the distances between the pixel centers. For singular regions (regions made of a single row or column), the perimeter returns twice the distance between the pixel centers. The conversion factor between pixels and meters is obtained by identifying the ship in a single image and comparing its measured length in pixels to its known length.

\section{Results}

In order to investigate if there are universal features of melt pond evolution, we analyze area-perimeter data obtained from the segmented images. The geometrical features of melt ponds and the complexity of their boundaries can be captured by the fractal dimension $D$, defined as

$P \sim \sqrt{A}^{D}$, 

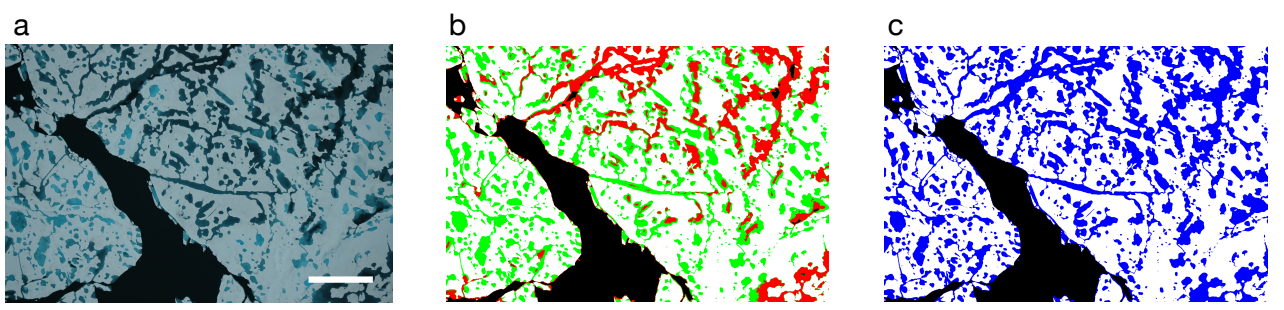

Fig. 2. Image segmentation for 14 August (HOTRAX). Starting with the original image in (a), the image is initially segmented in (b) using a four color threshold with ice, shallow ponds, deep ponds and ocean/deep ponds colored as white, green, red and black, respectively. In the last step, deep and shallow ponds are differentiated from ocean and recombined in the final white, blue and black image (c) for ice, melt ponds and ocean, respectively.

where $A$ and $P$ are the area and perimeter, respectively. On logarithmic scales the slope characterizing the $A-P$ data is one-half the fractal dimension. For regular objects like circles and polygons, the perimeter scales like the square root of the area, and $D=1$. For objects with more highly ramified structure, such as a Koch snowflake, $D>1$. As the boundary becomes increasingly complex and starts filling two dimensional space, $P \sim A$ and then $D \approx 2$. We remark that $D=2$ is the upper bound for the two dimensional fractal exponent, and corresponds to space-filling curves (Sagan, 1994).

Area-perimeter data were computed for 5269 melt ponds from a subset of segmented HOTRAX images for 22 August (Fig. 3a). Analysis of this data set shows that the trend in the data changes slope around a critical length scale of about $100 \mathrm{~m}^{2}$ in terms of area. In order to further investigate and better elucidate this interesting and unexpected phenomenon, we compute the fractal dimension $D(A)$ as a function of melt pond area $A$. Assuming from Eq. (1) that $P=k \sqrt{A}^{D}$ with $k>0$, then

$\log P=\frac{D}{2} \log A+\log k$,

and $\frac{D}{2}$ represents the slope of the logarithmic $A-P$ data in Fig. 3a. Since melt ponds with larger areas have more complex boundaries than smaller melt ponds, we assume that the slope $D(A)$ is a non-decreasing function of $A$. After ordering the points $\left(A_{i}, P_{i, j}\right)$ (for a given area $A_{i}$, there are multiple perimeter values $P_{i, j}$ ) lexicographically, we compute $m_{i, j}$, the slope between $\left(A_{i}, P_{i, j}\right)$ and its neighbors $\left(A_{m}, P_{m, j}\right)$ with $m>i$ until the non-decreasing condition $m_{i, j} \geq m_{i-1, j}$ is satisfied. $D_{i, j}$ is then defined as $2 m_{i, j}$. Repeating this procedure for all $i, j$ produces the graph in Fig. $3 b$.

We observe a rather dramatic transition from $D=1$ to $D \approx 2$ as the ponds grow in size, with the transitional regime centered around $100 \mathrm{~m}^{2}$. The three red triangles shown in Fig. 3a, from left to right, correspond to the three melt ponds shown in Fig. 3c. They are representative of the three regimes suggested by the graph of $D(A)$ :

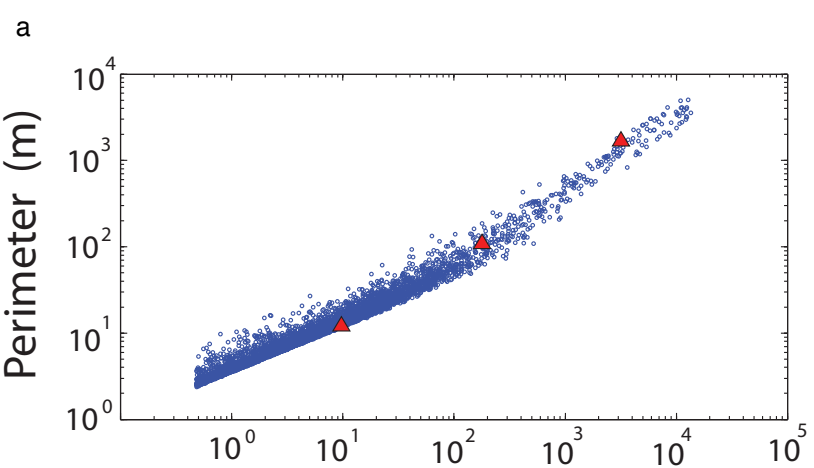

b

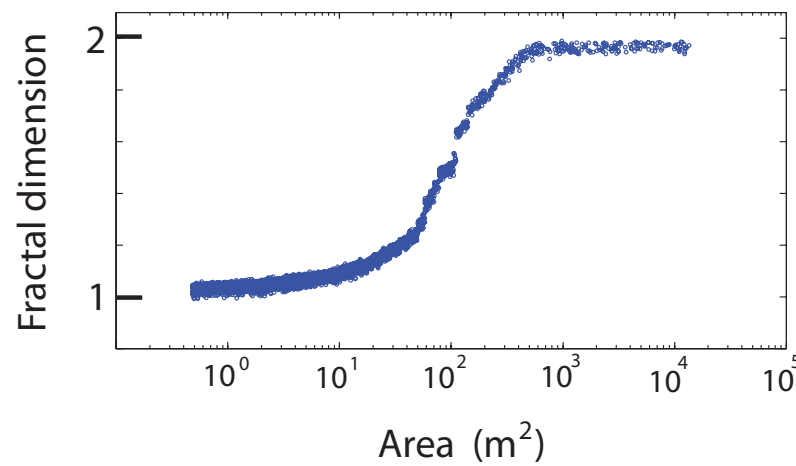

C

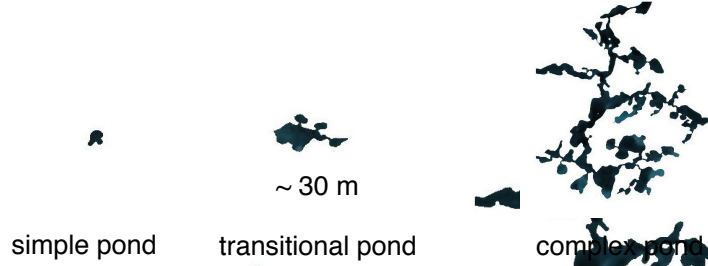

Fig. 3. Transition in fractal dimension. (a) Area-Perimeter data for August 22 (HOTRAX) displays a "bend" around a critical length scale of $100 \mathrm{~m}^{2}$ in area. (b) Graph of the fractal dimension $D$ as a function of area $A$, computed from the data in (a). The fractal dimension exhibits a transition from 1 to 2 as melt pond area increases from around $10 \mathrm{~m}^{2}$ to $1000 \mathrm{~m}^{2}$. The three red triangles, from left to right, correspond to typical ponds in each regime, which are shown in (c): a small pond with $D=1$, a transitional pond with a horizontal length scale of about $30 \mathrm{~m}$, and a large convoluted pond with $D \approx 2$. 
1. $A<10 \mathrm{~m}^{2}$ : simple ponds with Euclidean boundaries and $D \approx 1$.

2. $10 \mathrm{~m}^{2}<A<1000 \mathrm{~m}^{2}$ : transitional ponds where complexity increases rapidly with size.

3. $A>1000 \mathrm{~m}^{2}$ : self-similar ponds where complexity is saturated and $D \approx 2$.

The transitional length scale of about $100 \mathrm{~m}^{2}$, identified by the location of the "bend" in the $A-P$ data, appears to be about the same after analysis of hundreds of thousands of melt ponds from both SHEBA and HOTRAX.

\section{Discussion}

These results demonstrate that there is a separation of length scales in melt pond structure. Such findings can ultimately lead to more realistic and efficient treatments of melt ponds and the melting process in climate models. For example, a large connected pond which spans an ice floe is likely more effective at helping to break apart a floe than many small disconnected ponds. Moreover, a separation of scales in the microstructure of a composite medium is a necessary condition for the implementation of numerous homogenization schemes to calculate its effective properties. "Homogenization", also known as "upscaling", refers to a set of ideas and methods in applied mathematics which address the problem of computing the effective behavior of inhomogeneous media or systems. For example, consider an electrically insulating host containing uniformly dispersed conducting inclusions. Homogenization theory gives a range of mathematical techniques for obtaining rigorous information about the effective or overall conductivity of this composite (Milton, 2002; Torquato, 2002). Thus, the existence of a scale separation in the pond/ice composite implies that rigorous calculations of the effective albedo are amenable to powerful homogenization approaches. Similarly, techniques of mathematical homogenization can thus be applied to finding the effective behavior of transmitted light through melt ponds and its influence on the heat balance of the upper ocean and biological productivity. Our findings for the fractal dimension of the melt ponds and its variation are similar to results on the fractal dimensions of connected clusters in percolation and Ising models (Saleur and Duplantier, 1987; Coniglio, 1989).

Like melt ponds, clouds strongly influence Earth's albedo. However, the geometric structure of clouds and rain areas was found through similar calculations (Lovejoy, 1982) to have a fractal dimension of 1.35 . This result was constant over the entire range of accessible length scales, which is in stark contrast to what we find here for Arctic melt ponds. Interestingly, sea ice floe size distributions display a similar separation of scales with two fractal dimensions (Toyota et al., 2006).

To help understand the transitional behavior we observe in Fig. 3, we consider the process of how small simple ponds coalesce to form large, highly ramified connected regions. At the onset of melt pond formation, shallow ponds appear on the ice surface. These initial ponds are rather small on multiyear sea ice but can be more extensive on first-year ice. They are generally somewhat circular in shape and their boundaries are simple curves (Fig. 4a, photo taken 8 July). As melting increases, the area fraction $\phi$ of the ponds increases: Small ponds coalesce to form clusters, which themselves coalesce, and so on. The scale over which the melt phase is connected increases rapidly with this evolution, signaling a percolation threshold (Stauffer and Aharony, 1992; Torquato, 2002) at some critical area fraction $\phi_{\mathrm{c}}$. The value of $\phi_{\mathrm{c}}$ likely depends on the topography of the ice and snow surface, the age of the ice, and other local characteristics.

The transition to ponds which are just barely connected over the scale of the images is illustrated in Fig. $4 \mathrm{~b}$ (photo taken 8 July), which has $\phi \approx 25 \%$. This particular example is a reasonable candidate for a percolation threshold. Above this threshold, the ponds are connected on macroscopic scales much larger than the smaller, individual ponds which form the building blocks of larger structures (Fig. 4c, photo taken 22 August). Melt ponds whose boundary curve is highly convoluted can be connected on length scales larger than the available images, However, smaller disconnected melt ponds remain during the entire season.

Finally, we observe that the critical length scale for melt ponds is determined by the sizes of basic pond shapes which form the building blocks of large-scale connected networks. Each melt pond can be broken into basic parts of either thin elongated shapes, which we call bonds, or approximately convex shapes, which we call nodes. Using this terminology, the structure of a melt pond can be described as a locally tree-like network of nodes joined together through bonds. A simple melt pond with $D=1$ is a small network consisting of a single node or possibly a few connected nodes, while more complex melt ponds are networks consisting of many nodes and bonds. The distinction between transitional ponds and complex ponds $(D \approx 2)$ is achieved by looking at the self-similarity of melt ponds.

A melt pond is self-similar with respect to its areaperimeter relation if there exists a sub-pond (any connected part of a melt pond that remains after removing some nodes and bonds) such that the perimeter to area ratio of the entire melt pond is approximately the same as that of the sub-pond (Fig. 5). For example, by computing the perimeter to area ratios for the original melt pond $\mathcal{M}$ (Fig. 5a) and a sub-pond $\mathcal{M}_{1}$ (Fig. 5b) we find

$$
\frac{P(\mathcal{M})}{A(\mathcal{M})} \approx \frac{P\left(\mathcal{M}_{1}\right)}{A\left(\mathcal{M}_{1}\right)} \approx 0.068 \mathrm{~m}^{-1} .
$$

Hence, this melt pond is self-similar or complex. On the other hand, transitional ponds are not self-similar. Thus, selfsimilarity allows melt ponds to be classified based on their structure and hence fractal exponent. Moreover, the spatial 

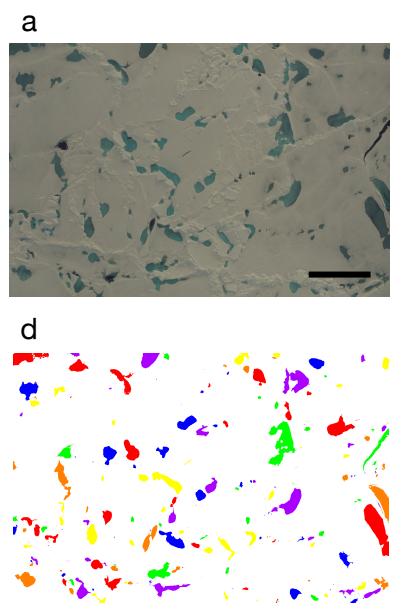

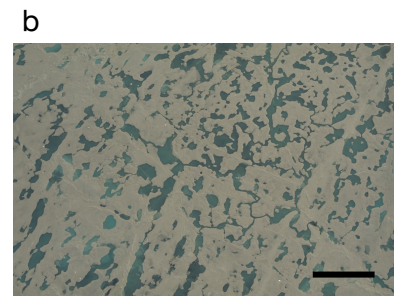

e

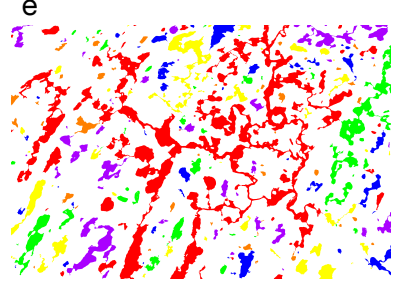

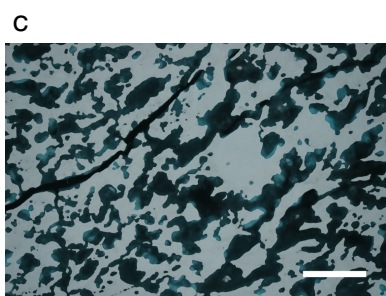

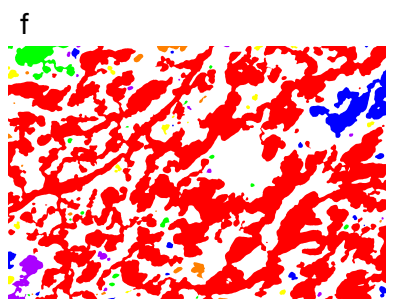

Fig. 4. Evolution of melt pond connectivity and color coded connected components. (a) Disconnected ponds, (b) transitional ponds, (c) fully connected melt ponds. The bottom row shows the color coded connected components for the corresponding image above: (d) no single color spans the image, (e) the red phase just spans the image, (f) the connected red phase dominates the image. The scale bars represent $200 \mathrm{~m}$ for (a) and (b), and $35 \mathrm{~m}$ for (c).

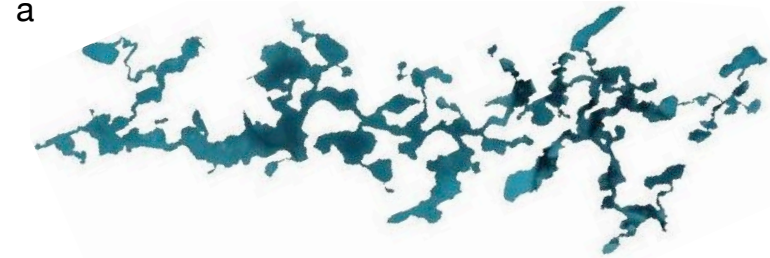

b

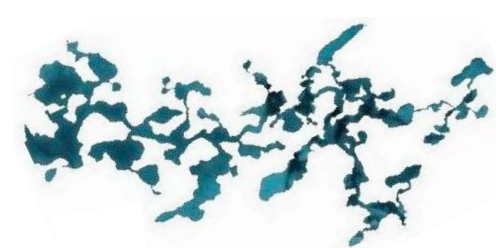

Fig. 5. Self-similar melt pond. A melt pond $\mathcal{M}$ in (a) and one of its subponds $\mathcal{M}_{1}$ in (b) have the same perimeter to area ratio. $\mathcal{M}$ is then self-similar or complex with $D \approx 2$.

scales of the transitional ponds determine the transitional scale regime for the fractal dimension.

\section{Conclusions}

Accounting for the complex evolution of Arctic melt ponds and its impact on sea ice albedo is a key challenge to improving projections of climate models. Our results yield fundamental insights into the geometrical structure of melt ponds and how it evolves with increased melting. The separation of scales and fractal structure provide a basis for new approaches to melt pond characterization and the efficient representation of their role in climate models, as well as a rig- orous framework for further investigations. For example, the calculation of sea ice albedo involves an understanding of ice floe and open water configurations, as well as melt pond configurations on the surface of individual sea ice floes. Our findings yield new insights into the problem of calculating ice floe albedo from knowledge of melt pond geometry and its evolution.

We believe that our results serve as a benchmark against which current numerical models of melt pond evolution (Flocco and Feltham, 2007; Flocco et al., 2010; Scott and Feltham, 2010) could be tested. These melt pond models could possibly be tuned to produce the transition in fractal dimension that we observe in actual melt pond images. Moreover, these findings can provide a fundamental constraint for existing parameterizations of melt ponds and their effects in larger-scale climate models (Pedersen et al., 2009; Holland et al., 2012; Polashenski et al., 2012).

Furthermore, the transmittance of light through melt ponds is an order of magnitude greater than it is through the ice itself (Frey et al., 2011). We believe that our results on melt pond geometry and connectedness will help explain the complex transmitted radiation fields observed under melting sea ice (Frey et al., 2011), and facilitate modeling of the heat balance of sea ice and the upper ocean.

Finally, biological productivity in the ice covered upper ocean is dependent upon light penetrating through the sea ice pack. Recently, a massive phytoplankton bloom was observed underneath melting Arctic sea ice (Arrigo et al., 2012). Again, we believe that our findings will provide insights into understanding this phenomenon and aid in efforts at modeling such communities, their evolution, and their interaction with solar radiation via the sea ice pack and the melt ponds above. 
Acknowledgements. We are grateful for the support provided by the Division of Mathematical Sciences (DMS), the Arctic Natural Sciences (ARC) Program, and the Office of Polar Programs (OPP) at the US National Science Foundation (NSF). Kyle Steffen was supported by the NSF Research Experiences for Undergraduates (REU) Program through an NSF VIGRE grant to the Mathematics Department at the University of Utah, and a Global Change and Ecosystem Center Graduate Fellowship from the University of Utah. Bacim Alali was supported by an NSF Lorenz Postoctoral Fellowship in Mathematics of Climate and by the Scientific Computing and Imaging Institute at the University of Utah.

Edited by: D. Feltham

\section{References}

Arrigo, K. R., Perovich D. K., Pickart R. S., Brown Z. W., van Dijken G. L., Lowry K. E., Mills M. M., Palmer M. A., Balch W. M., Bahr F., Bates N. R., Benitez-Nelson C., Bowler B., Brownlee E., Ehn J. K., Frey K. E., Garley R., Laney S. R., Lubelczyk L., Mathis J., Matsuoka A., Mitchell B. G., Moore G. W. K., Ortega-Retuerta E., Pal S., Polashenski C. M., Reynolds R. A., Scheiber B., Sosik H. M., Stephens M., and Swift J. H.: Massive phytoplankton blooms under Arctic sea ice, Science, 336, 6087, doi:10.1126/science.1215065. 2012.

Boé, J., Hall, A., and Qu, X.: September sea-ice cover in the Arctic Ocean projected to vanish by 2100 , Nat. Geosci., 2, 341-343, 2009.

Christensen, K. and Moloney, N. R.: Complexity and Criticality, Imperial College Press, London, 2005.

Coniglio, A.: Fractal structure of Ising and Potts clusters: Exact results, Phys. Rev. Lett., 62, 3054-3057, 1989.

Eicken, H., Krouse H. R., and Perovich, D. K.: Tracer studies of pathways and rates of meltwater transport through Arctic summer sea ice, J. Geophys. Res.-Oceans, 107, 8046, doi:10.1029/2000JC000583, 2002.

Eicken, H., Grenfell, T. C., Perovich, D. K., Richter-Menge, J. A., and Frey, K.: Hydraulic controls of summer Arctic pack ice albedo, J. Geophys. Res.-Oceans, 109, C08007, doi:10.1029/2003JC001989, 2004.

Flocco, D. and Feltham, D. L.: A continuum model of melt pond evolution on Arctic sea ice, J. Geophys. Res., 112, C08016, doi:10.1029/2006JC003836, 2007.

Flocco, D., Feltham, D. L., and Turner, A. K.: Incorporation of a physically based melt pond scheme into the sea ice component of a climate model, J. Geophys. Res., 115, C08012, doi:10.1029/2009JC005568, 2010.

Frey, K. E., Perovich, D. K., and Light, B.: The spatial distribution of solar radiation under a melting Arctic sea ice cover, Geophys. Res. Lett., 38, L22501, doi:10.1029/2011GL049421, 2011.

Holland, M. M., Bailey, D. A., Briegleb, B. P., Light, B., and Hunke, E: Improved sea ice shortwave radiation physics in CCSM4: The impact of melt ponds and aerosols on Arctic sea ice, J. Climate, 25, 1413-1430, doi:10.1175/JCLI-D-11-00078.1, 2012
Hunke, E. C. and Lipscomb, W. H.: CICE: the Los Alamos Sea Ice Model Documentation and Software User's Manual Version 4.1 LA-CC-06-012, T-3 Fluid Dynamics Group, Los Alamos National Laboratory, 2010.

Lovejoy, S.: Area-perimeter relation for rain and cloud areas, Science, 216, 185-187, 1982.

Milton, G. W.: Theory of Composites, Cambridge University Press, Cambridge, 2002.

Pedersen, C. A., Roeckner, E., Lüthje, M., and Winther, J.: A new sea ice albedo scheme including melt ponds for ECHAM5 general circulation model, J. Geophys. Res., 114, D08101, doi:10.1029/2008JD010440, 2009.

Perovich, D. K., Tucker III, W. B., and Ligett, K.: Aerial observations of the evolution of ice surface conditions during summer, J. Geophys. Res., 107, 8048, doi:10.1029/2000JC000449, 2002.

Perovich, D. K., Richter-Menge, J. A., Jones, K. F., and Light, B.: Sunlight, water, and ice: Extreme Arctic sea ice melt during the summer of 2007, Geophys. Res. Lett., 35, L11501, doi:10.1029/2008GL034007, 2008.

Perovich, D. K., Grenfell, T. C., Light, B., Elder, B. C., Harbeck, J., Polashenski, C., Tucker III, W. B., and Stelmach, C.: Transpolar observations of the morphological properties of Arctic sea ice, J. Geophys. Res., 114, C00A04, doi:10.1029/2008JC004892, 2009.

Polashenski, C., Perovich, D., and Courville, Z.: The mechanisms of sea ice melt pond formation and evolution, J. Geophys. Res.Oceans, 117, C01001, doi:10.1029/2011JC007231, 2012.

Sagan, H.: Space-Filling Curves, Springer Verlag, New York, 1994.

Scharien, R. K. and Yackel, J. J.: Analysis of surface roughness and morphology of first-year sea ice melt ponds: Implications for microwave scattering, IEEE Trans. Geosci. Rem. Sens., 43, 2927, doi:10.1109/TGRS.2005.857896, 2005.

Saleur, H. and Duplantier, B.: Exact determination of the percolation hull exponent in two dimensions, Phys. Rev. Lett., 58, 23252328, 1987.

Scott, F. and Feltham, D. L.: A model of the three-dimensional evolution of Arctic melt ponds on first-year and multiyear sea ice, J. Geophys. Res., 115, C12064, doi:10.1029/2010JC006156, 2010.

Serreze, M. C., Holland, M. M., and Stroeve, J.: Perspectives on the Arctic's shrinking sea-ice cover, Science, 315, 1533-1536, 2007.

Skyllingstad, E. D., Paulson, C. A., and Perovich, D. K.: Simulation of melt pond evolution on level ice, J. Geophys. Res., 114, C12019, doi:10.1029/2009JC005363, 2009.

Stauffer, D. and Aharony, A.: Introduction to Percolation Theory, Second Edition, Taylor and Francis Ltd., London, 1992.

Stroeve, J., Holland, M. M., Meier, W., Scambos, T., and Serreze, M.: Arctic sea ice decline: Faster than forecast, Geophys. Res. Lett., 34, L09591, doi:10.1029/2007GL029703, 2007.

Thompson, C. J.: Classical Equilibrium Statistical Mechanics, Oxford University Press, Oxford, 1988.

Torquato, S.: Random Heterogeneous Materials: Microstructure and Macroscopic Properties, Springer-Verlag, New York, 2002.

Toyota, T, Takatsuji, S., and Nakayama, M.: Characteristics of sea ice floe size distribution in the seasonal ice zone, Geophys. Res. Lett., 33, L02616, doi:10.1029/2005GL024556, 2006. 